\title{
Effect of Instructional Strategies on Students' Academic Achievement in Public Senior High Schools in Ghana
}

\author{
Richard Kwabena Akrofi Baafi, ${ }^{1, *}$ \\ ${ }^{1}$ Faculty of Education and Psychology, Eötvös Loránd University (ELTE), Hungary \\ *Corresponding author: Faculty of Education and Psychology, Eötvös Loránd University \\ (ELTE), Hungary. E-mail: dukeobonyo@yahoo.com
}

Received: February 20, 2020

Accepted: April 20, 2020 Published: May 6, 2020

doi:10.5296/ije.v12i2.16978

URL: https://doi.org/10.5296/ije.v12i2.16978

\begin{abstract}
Teaching quality, as demonstrated by effective teacher instructional strategies, has dominated education process research in the recent past. This study sought to establish the effect of instructional strategies on student academic achievement in public senior high schools in Ghana. The study utilised a sample of 210 students and 160 teachers sampled through proportionate stratified sampling. The study attempted to establish which instructional strategies were inherent in public senior high schools in Ghana and how those strategies influenced students' achievement in the national standardised mathematics test. The study found out that most teachers had an average experience of five years, with those over ten years' experience exhibiting ineffective teaching strategies due to lack of structured teacher professional development. Further, the study established that classroom management strategies which promote discipline among students and teacher-prepared strategies were inherent among teachers. However, strategies which increase learner engagement, as well as those which increase learning during lesson delivery, were inadequate. The study recommends that the government of Ghana enhances a structured teacher professional development as well as effective school-based teacher supervision policies.
\end{abstract}

Keywords: instructional strategies, student achievement, school environment 


\section{Introduction}

In recent times, studies on school finance and education outcomes have focused more on the role of the teacher in improving learning outcomes. This is a slight deviation from the usual education production functions which allude that inputs into an education system have commensurate outputs. Evidence has it that despite significant efforts in school financing and provision of learning and teaching resources (in the form of teachers, books, and physical learning facilities), a great variance is experienced from school to school, and from classroom to classroom. These variations have refocused the attention of many scholars into within-school, and within-class factors which influence learning outcomes. As such, school quality, teacher quality, and teaching quality are currently dominating the education learning discourse. Instructional strategies refer to the techniques and methodologies teachers apply to aid students in the learning process (Curtiss et al., 2016). These instructional strategies form the epicentre of teaching quality and by extensions classroom quality. Various instructional strategies exist and are applied in various contexts for different anticipated outcomes (Morrison, Ross, Morrison, \& Kalman, 2019)

Many studies in education process research have classified Instructional strategies into active learning, group-based learning, assessment-based learning, and enquiry-based learning (IBL). Further classification based on action origin, group the strategies into learner-centred, teacher-centred or an integrated instructional strategy (Illeris, 2018). Different instructional strategies fit different learning settings and elicit various anticipated outcomes (Morrison et al., 2019). While learner-centred instructional strategies have been preferred (based on recent research findings on its effectiveness), the three instructional strategies present different advantages and disadvantages which inform teachers strategy preference (Curtiss et al., 2016). In most cases, teachers adopt strategies that make their work easier based on their perceptions and attitude, personal subjective preferences, and institutional and disciplinary cultures. Besides, teachers also vary the type and quality of instructional process based on the entry behaviour of the learners as well as their level of engagement.

In this regard, teachers based on the context of the learning environment, adopt different instructional strategies which ultimately result in within school and among class variances in student learning outcomes (Illeris, 2018). In Ghana, the need for an enhanced learning outcome has led to various reforms in the education sector. The reforms range from a well-structured teaching education system which enhances teacher quality, continuous teacher professional development, and regular teacher monitoring and evaluation of teaching and learning process. Such reforms envision the application of appropriate instructional strategies for better learning outcome (Adu-Gyamfi, Donkoh, \& Addo, 2016). This paper argues that while learning is conceptualised as a holistic social outcome, success in education is based on academic achievement, which is greatly influenced by teaching quality (Illeris, 2018). Available studies have concentrated on the effectiveness of various learning strategies and factors associated with learning outcomes. This study investigates the effects of instructional strategies on academic achievement in public senior high schools in Ghana. 


\section{Literature Review}

\subsection{Teacher-Centred Instructional Strategies}

Teacher-centred instructional strategy refers to teaching techniques in which learning activities are centred on the teacher (Baeten, Dochy, Struyven, Parmentier, \& Vanderbruggen, 2016). In this strategy, the teacher is the ultimate authority figure and students viewed as without knowledge of the instructional content and are expected to passively absorb knowledge. The teacher, in front of the students, profess knowledge through direct instruction with an aim that upon assessment, students will post good results based on what the teacher instructed them on. In this strategy, objectively scored tests and assessments are indicators of learning (van de Kuilen, Altinyelken, Voogt, \& Nzabalirwa, 2019). Examples of teacher-centred instructional strategies include teacher talks commonly known as lecturing, class demonstrations, giving assignments and homework, memorising, and reviewing (Baeten et al., 2016). Other methods include reviewing, questioning, class discussions, and class discussions. In such methods, learning follows certain curricula, and the success of the process is based on the completion of the set curricula. Students are often expected to take notes based on the knowledge professed in class. Similarly, tests and examinations are based on the set curricula and success in the examinations based on a set scheme. Since teachers are the ultimate source of information in this strategy, questions raised by students are expected to be answered directly by the teachers and students are not, in most cases, given a chance for involvement. The teacher controls every learning experience by subjectively designing class activities (Di Biase, 2019).

Advantages of the teacher-centred instructional strategies are that it is suitable for large classes where it is practically impossible to cater to the learning needs of individual students. The strategy also draws its advantage from the fact that it allows a shorter time for class activities. It also allows teachers to adequately prepare learning materials since a single learning material caters for all students. The strategy also provides for teacher inadequacies, including a feeling of nervousness, embarrassments, or getting tongue-tied. Also, the strategy promotes a logical arrangement of content or subject matter of the instructional process such that irrelevant material or subject is avoided. Since the teacher designs the curriculum in the case of the teacher-centred instructional strategy, desired learning goals can easily be achieved (Baeten et al., 2016). Historically, teacher-centred instructional strategies have been applied for its main advantages in cases where the main aim of education has been the transfer of knowledge. Teacher-centred instructional strategies are the most common instructional strategies and especially in resource-limited environments (Starkey, 2019).

However, teacher-centred instructional strategies have been criticised for an inability to spur learner attitude change, which in part, is one of the objectives of learning. The other major dilemma of the strategy is the lack of sources and resources. This is especially true, given the fact that all knowledge is expected from one source (Di Biase, 2019). In applying teacher-centred instructional methods, rigid administration, planning and management hinder innovativeness and knowledge exploration. Critics of the strategies also argue that common standards in various learning institutions cannot be maintained given the subjective knowledge sourcing applied in the strategy. The strategy also presents a dilemma on the appropriate 
curriculum for teacher training institutions (Starkey, 2019).

\subsection{Learner-Centred Instructional Strategies}

Learner-centred instructional strategies are based on learning responsibilities and facilitative nature of the teacher (Olayinka, 2016). In these strategies, the student is responsible for learning, and the teacher ensures that the learning process is facilitated. The strategies are based on the need to train students based on their nature and not what "others" want. Learning is, thus, arranged on a model based on the students' interest, knowledge and needs. The main aim of the strategies is to make students attain skills to explore their learning features so as to allow students to learn how to learn in the process (Sakata, 2019). Prominent features of learner-centred instructional methods include collaborative learning, critical thinking and connecting information to previous knowledge. For this reason, the strategies have been referred to as interactive learning. The learning process, as such, involves facilitating the presentation of questions for small group work. It may also present an opportunity for the use of media and student fieldwork involvement. The strategies are grouped in broad methods, including inquiry-based learning, case-based learning, problem-based learning, project-based learning, discovery learning, and just-in-time teaching (Sakata, 2019).

The advantages of the strategies are diverse. Proponents applaud the strategies for the fact that they enable diverse learning styles and at the same time, encourage the active involvement of all students while facilitating individual improvement of weaknesses (Starkey, 2019). The strategies provide an opportunity for students to ask questions, lead conversations and define problems. In this way, the strategies aid the connection of students' world with classroom learning pursuits. It has also been argued that when learners are facilitated to share experiences through group discussions, application of acquired knowledge and skills is enhanced (Starkey, 2019). Learner-centred instructional strategies involve democratic participation of all students in the learning process and thereby, encouraging critical thinking and enhance learning outcomes. The strategies also cater to students' communication needs. The strategies, however, are not without blame. Critics of the strategies argue that since they encourage students' participation and thus discussions and talking among students, they present a chaotic classroom. The student-centred teacher also has the disadvantage of having to manage all students' activities at once, which in a real sense, is a tall order when students are working on different stages of the same project. Moreover, evidence has alluded that some students may miss important facts since the strategies do not allow instructors to deliver instruction at once for all students. Finally, in cases where students' preference to work alone is evidenced, group work becomes most inappropriate (Starkey, 2019).

Interest in student-centred instructional strategies has gained momentum across the world. Most studies have found evidence for better learner outcome with learner-centred instructional strategies. Positive impacts of the strategies have been documented by researchers such as Li, Flowerdew, and Cargill (2018), Kang and Keinonen (2018) as well as Day, Gu, and Sammons (2016) who indicated that the strategies enhance learning achievement better than the traditional teacher-centred instructional strategies. Day et al. (2016), also established that learner-centred instructional strategies produce higher impact 
holistic learning achievement. Other scholars have also demonstrated that learner-centred instructional methods are best suitable for teaching complex academic materials and can suitability aid teachers in accomplishing social learning and interpersonal relations (McKnight et al., 2016).

\subsection{Integrated Instructional Strategies}

The concept of integrated instructional strategies is modelled, along with the pros of both teacher-centred and learner-centred instructional strategies (Chick \& Hassel, 2009). The strategy is achievable through an integrated curriculum that connects the various areas of learning by cutting across subject-matter lines and emphasizing unifying concepts. The focus is to make connections for students and thus allowing them to engage in relevant, meaningful activities that can be connected to real-life (Riordan, Hine, \& Smith, 2019). The approach encourages exploration, information gathering and processing, presentation and refining of information about learning areas without constraints of the traditional barriers. An integrated instructional strategy teacher applies lecture methods, use of PowerPoints, performance-oriented techniques, journal writing and drawing maps, use of audio-visuals, group discussions and demonstrations to achieve learning outcomes. The strategy encourages students to see the interconnectedness and interrelationships between the curriculum areas. Further, the strategy does not focus on learning in isolated curriculum areas but is rather based on skill development around a central theme, relevant to learners (Day et al., 2016).

Central to the strategy is the inquiry approach. The approach is premised on the need to make students active learners. As active students conduct research, interpret their findings, communicate such findings and ultimately process learning to both others and themselves. Such an approach allows for students to construct meaning using their prior knowledge on a subject, and new knowledge gained during the learning process (Riordan et al., 2019). The main advantage of the integrated learning strategy is that it accommodates many learning styles, theories as well as intelligence. The strategy also allows connection among different disciplines. Use of relevant real-life experiences as advocated for by the strategy infers advantage of active learner participation. The integrated curricula also lay the foundation for deeper content understanding. Also, the strategy has been applauded for its focus on basic skills, content and stimulation of higher-level thinking. Use of this strategy has been justified by the fact that there would not be enough time in the ideal teaching scenario to teach everything in isolation. The strategy, therefore, is ideal for creating positive and collaborative learning environments (Day et al., 2016).

The method draws its weaknesses on the fact that its application does not allow time for effective planning of learning areas. The other bottleneck in the application of integrated strategy is having to integrate different types of information, induce high cognitive load and overwhelm the learners (Riordan et al., 2019). The strategy also requires that learners allocate and regulate their cognitive resources adequately during learning to enable them to use simultaneously acquired informative productively in the learning process (Drinkwater et al., 2014). This, therefore, implies that in cases where topics are presented in a complex, integrated way, the student must switch back and forth between perspectives to form a coherent mental 
representation. The other disadvantage is that in cases where learners with different knowledge levels are subjected to same task assignments, those with some level of prior knowledge are more likely to be overwhelmed. It can also be reasoned that students in an integrated-learning strategy classroom may differ in their general ability to control attention to keep required information in an active and quickly retrievable state and thereby presenting the challenge of differentiated learning outcome (Riordan et al., 2019).

\section{Methodology}

This study utilised a descriptive survey research design. A sample of 120 students and 60 teachers was utilised in the study. To be able to analyse within student differences across subjects, we limited the sample to school classes where teachers have taught students for at least one year to avoid errors of endogeneity.

\subsection{Variables and Sample Size}

The main independent variable included the four dimensions of instructional practices which included classroom instructional strategies geared towards discipline and class control, classroom instructional strategies geared towards lesson preparedness and delivery, leaner cantered strategies, and integrated instructional strategies. A composite variable was generated for items assessing each dimension of instructional strategies. The dependent variables included students' achievement, which was a standardised value of end term examination score in integrated science. The choice of mathematics subject is because of its unique instructional approach. We use the grades in written examinations because these can be regarded as being more objective compared to scores in usual formative examinations since all schools are required to use standardised examination questions issued by Ghana Education Service with general standards for the use of each score on a continuous scale. The control variables included age and gender of the teacher and the student, classroom size, educational level and experience of the teacher. The dummy variable "discipline" was factored into the model to minimise errors associated with estimating the effects of teacher instructional strategies on student achievement. Items on a discontinuous scale were measured on a Likert scale with five response categories ( 1 = "Strongly disagree," 2 = "Disagree," 3 = "Neutral," 4 = "Agree," $5=$ "Strongly agree") in line with previous studies on teacher instructional strategies and student achievement (Andersen \& Reimer, 2019). Collected data was cleaned and coded in line with the objectives. A sample of 370 respondents was selected for the study. It consisted of 120 teachers and 250 students selected through proportionate stratified sampling.

\subsection{Data Analysis}

Within an education production function framework, the effect of teacher instructional strategies was estimated using the following analytical model:

$$
\mathrm{Yij}=\mathrm{Boij}+\mathrm{Sij}+\mathrm{Tij}+\mathrm{X} \mathrm{ij}+\mathrm{GMij}+\alpha
$$

Where Yij denotes the achievement of the $\mathrm{i}^{\text {th }}$ student in the $\mathrm{K}^{\text {th }}$ School and is a function of a vector of school/classroom characteristics (S), subject-teacher characteristics (T), and 
individual student background characteristics (X) and teacher instructional strategies (GM). Since we did not include within-student and within-class estimation in our analysis, we, therefore, included within-class and within-class controls. Dimensions of instructional strategies and their indicators are as shown below.

Table 1. Dimensions of Instructional Management

\begin{tabular}{|c|c|c|}
\hline Dimensions & Indicators & Scale \\
\hline $\begin{array}{l}\text { Classroom instructional } \\
\text { management strategies } \\
\text { (discipline and class control) }\end{array}$ & $\begin{array}{l}\text { 1. Teacher minimises disruptive behaviours among } \\
\text { learners } \\
\text { 2. Teacher Often warns students with sanctions } \\
\text { 3. Teachers ensure learners understand how } \\
\text { discipline will affect their performance. }\end{array}$ & $\begin{array}{l}\text { 5-point scale from } 1 \\
\text { (disagree) to } 5 \text { (agree) }\end{array}$ \\
\hline $\begin{array}{l}\text { Classroom Instructional } \\
\text { management strategies } \\
\text { (Preparedness and delivery) }\end{array}$ & $\begin{array}{l}\text { 1. Teacher states learning objectives to learners } \\
\text { 2. Teacher delivers the lesson at the pace of leaners } \\
\text { 3. Teacher uses Q/A to ensure learners comprehend } \\
\text { the lessons }\end{array}$ & $\begin{array}{l}\text { 5-point scale from } 1 \\
\text { (disagree) to } 5 \text { (agree) }\end{array}$ \\
\hline Learner-centred strategies & $\begin{array}{l}\text { 1. The teacher helps learners with learning } \\
\text { difficulties } \\
\text { 2. The teacher moves at the pace of slow learners } \\
\text { 3. The teacher pays close attention to the learning } \\
\text { needs of all children in the class } \\
\text { 4. Encourage students of mixed abilities to work } \\
\text { together }\end{array}$ & $\begin{array}{l}\text { 5-point scale from } 1 \\
\text { (disagree) to } 5 \text { (agree) }\end{array}$ \\
\hline $\begin{array}{l}\text { Integrated instructional } \\
\text { strategies }\end{array}$ & $\begin{array}{l}\text { 1. Teacher uses ICT in teaching } \\
\text { 2. Teacher uses Inquiry-based instruction like } \\
\text { discussion and } Q / A \text { in teaching. }\end{array}$ & $\begin{array}{l}\text { 5-point scale from } 1 \\
\text { (disagree) to } 5 \text { (agree) }\end{array}$ \\
\hline
\end{tabular}

\subsection{Descriptive Statistics}

Table 2. Descriptive Statistics

\begin{tabular}{|c|c|c|c|c|}
\hline Variables & Mean & SD & Min & Max \\
\hline 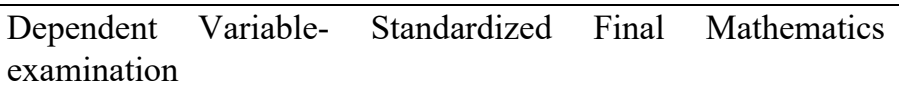 & 1.6 & 0.94 & 2.53 & .82 \\
\hline Teacher experience & 12.73 & 1.64 & 1 & 14 \\
\hline Teachers gender & 1.2 & 0.97 & 1 & 1 \\
\hline Gender of the student & 1.1 & 0.87 & 1 & 1 \\
\hline Age of the student & 14.7 & .93 & 13 & 15 \\
\hline Classroom size. & 46.3 & 1.23 & 40 & 54 \\
\hline $\begin{array}{l}\text { Composite value for Classroom instructional management } \\
\text { strategies (discipline and class control) }\end{array}$ & 2.85 & 0.67 & 1 & 4 \\
\hline $\begin{array}{l}\text { Composite value for Classroom Instructional management } \\
\text { strategies (Preparedness and delivery. }\end{array}$ & 2.17 & 1.1 & 1 & 4 \\
\hline Composite value for Learner-centred strategies & 2.28 & 0.76 & 1 & 5 \\
\hline Composite value for Integrated instructional strategies & 2.01 & 0.87 & 1 & 5 \\
\hline
\end{tabular}


The gender of the teacher, education level, experience, and the class size was controlled to ensure to minimise errors associated with the endogeneity of variables in the estimation of instructional strategies which influence student achievement.

Table 3. Coefficient Alphas and Inter-correlations between Variables in the Present Study.

\begin{tabular}{lllllllllll}
\hline & 1 & 2 & 3 & 4 & 5 & 6 & 7 & 8 & 9 & 10 \\
\hline Student achievement & - & & & & & & & & \\
Teachers experience & $.245^{*}$ & - & & & & & & & \\
Teachers education level & $.254^{* *}$ & $.213^{* *}$ & - & & & & & & \\
Teachers gender & $.597^{* *}$ & $.464^{*}$ & $.76^{* *}$ & - & & & & & \\
Classroom size & -.265 & $.244^{*}$ & -.238 & .384 & - & & & & \\
Classroom management & .15 & $.06^{*}$ & -.04 & .22 & -.28 & - & & & \\
(des) & & & & & & & & & \\
Learner-centered strategies & .01 & .35 & .03 & -.36 & -.32 & .02 & & & \\
Learner-centered strategies & .03 & .36 & $.13-$ & $-.14^{*}$ & -.26 & .01 & .35 & & \\
Classroom preparedness & .02 & .54 & $.28^{*}$ & $.29^{*}$ & -.04 & .05 & .25 & .08 & \\
Maths teaching experience & $.03 *$ & $.26 *$ & .04 & $.26^{*}$ & -.025 & .26 & .46 & .27 & 0.12 & - \\
\hline
\end{tabular}

1. Note. $\mathrm{N}_{-}$380. Thus, the correlations and significance tests associated with independent variables and dependent variables.

2. $*^{*} p_{-} .10$, two-tailed.

From the results above, almost all the variables in the study were associated with student mathematics achievement, of course, at different significance levels. From the correlation results, the use of learner-centred strategies and classroom preparedness strategies were positively associated with learning achievement. The two teacher variables, i.e. teacher experience and education levels, were positively but insignificantly associated with student achievement. The descriptive statistics further suggests a significant association between learner-centred strategies and learning achievement. The descriptive statistics also indicate a negative association between learner-centred approaches and classroom sizes. Meaning that it is not possible for teachers to use learner-centred approaches in classrooms with a large student population. These findings concur with those of Jones (2007), who found that there was a gender dimension on the effect of class sizes and the use of learner-centred approaches.

\section{Results}

The analysis was carried using hierarchical multiple regression. It was carried out in three steps starting with the control variables, i.e. gender of the teacher, education level, and experience, then the classroom variables were introduced into the model, and lastly, the composite variables for each instructional strategies were introduced into the model all at once. The impact value was ascertained by use of R-Squared, which measured the proportion 
of variance in student achievement, which can be attributed to the control variables, as well as teacher instructional strategies. The results of the regression analysis are as shown in table 4.

Table 4. Regression Analysis

\begin{tabular}{llll}
\hline & $(\mathrm{I})$. & $(2)$. & $(3)$. \\
\hline Teacher characteristics & & & \\
Education level & $-.018(.009)$ & $.005(.037$ & $028(.011)$ \\
Teaching experience & $.006(.011)$ & $.029(.022)$ & $.124(.041)$ \\
Teacher gender & $.023(.026)$ & $.008(.028)$ & $.001(.004)$ \\
Mathematics classroom teaching experience & $.006(.011)$ & $.029(.022)$ & $.057(.038)$ \\
Classroom variables & & & \\
Class size & & $.006(.011)$ & $.057(.038)$ \\
Instructional strategies & & & $.067(.032)$ \\
Classroom management (discipline) & & & $.029(.005)$ \\
Teacher instructional preparedness & & & $.032(.014)$ \\
Learner-centred strategies (for engagement) & & & $.023(.022)$ \\
Learner-centred strategies (instruction delivery) & & $.180(.074)^{*}$ & $.175(.113)^{*}$ \\
Constant & $.263(0.01)^{* * *}$ & 140 & 140 \\
Number of teachers & 140 & & \\
\hline
\end{tabular}

Note: $* p<.05, * * p<.01, * * * p<.001$. Figures in brackets are standard errors

In this section, we discuss the validity of the results in light of specific institutional features of the Ghanaian school system and robustness checks. Although the within-student across subject model addresses several methodological challenges, certain issues remain. An important one is the non-random assignment of students to classes and teachers based on subject-specific propensity for achievement. This is particularly problematic since we are not able to control for students' prior ability in mathematics. The reason why we didn't choose to control for students' prior achievement in mathematics since students sit for the internal mathematics examination several months before the final standardized mathematics examination. From the results in table 4 above, it is evident that teacher years of teaching experience despite controlled was associated to student achievement $(\beta=.124(.041))$, while teacher education level and gender were negatively associated to student achievement $(\beta=.028(.011)$ and $(\beta=. .001(.001)$ respectively.

This implied that the teacher level of education is not closely associated with superior instructional strategies hence student achievement. However, this does not deviate from previous scholarly evidence which alluded that a teacher's mastery of content is higher among well-educated teachers than those least educated. The findings from the table above also indicate that a teacher's gender is positively associated with learners mathematics 
achievement $(\beta=. .001(.004))$. Previous studies demonstrated a gender influence of teachers on student achievement with respect to variance in teaching strategies implying increased pedagogical efficiency, at least in instructional processes where a male teacher teaches boys. However, although adding information on instructional strategies significantly reduces same-gender teacher effect on students' academic achievement, it does not diminish it.

With regard to teachers' instructional strategies, teachers who are in a position to maintain learners classroom discipline during instructional time positively and significantly influence student academic achievement $(\beta=.067$ (.032) Disruptive students negatively influence the learning process by wasting quality learning time. Most indiscipline students may not do their homework or may lack student-teacher engagement. This behaviour has been found to interfere with learning time, especially from novice teachers. Teachers who minimize disruptive behaviours among learners may create a conducive learning environment by minimising wastage of quality learning time which translates to positive learning outcomes.

The study further established that teachers with effective instructional preparedness positively influenced learning outcomes $(\beta=.029$ (.005). In a typical instructional preparedness scenario in Ghana, a teacher is meant to ensure he or she has prepared all the required professional documents which include but not limited to schemes of work, lesson notes, lesson plans and a learning evaluation matrix. This will ensure that whatever is planned is what is taught and evaluation during each learning time. With regards to instructional strategies geared towards engagement, the study established that teachers who utilized learner instructional strategies geared towards promoting learner engagement towards learning positively influenced student academic achievement. Instructional strategies which help learning engagement include those which fully promote inquiry-based learning, which is developed in from known to unknown or from lower order to high order (constructivism) and those which in general promote enthusiasm in learning.

Further, regarding different dimensions of instructional strategies, the study established that Classroom management strategies which revolved around learners' engagement were positively associated with the student learning outcomes. Activities which will increase learning engagement range from student behavioural engagement, emotional engagement, and cognitive engagement. With behavioural engagement, students who are behaviorally engaged would typically comply with behavioural norms, such as attendance and involvement, and would demonstrate the absence of disruptive or negative behaviour. With emotional engagement, students who engage emotionally would experience affective reactions such as interest, enjoyment, or a sense of belonging. With cognitive engagement, cognitively engaged students would be invested in their learning, would seek to go beyond the requirements, and would relish the challenge. All these dimensions, through classroom observations, were inherent in Ghanaian classrooms, and this was established to be positively associated with learning achievement $(\beta=.032(.014)$. Lastly, about learner-centred strategies (instruction delivery), the study established that instructional strategies which result from effective teacher preparedness were positively associated with learning outcomes. In Ghana, the education act of 1976 requires teachers to be fully prepared for the instructional process. This preparedness involves teachers processing of schemes of work as well as lesson plans 
which outline goals, objectives, and targets to be realised from the learning outcomes. Therefore, this study argues that such well-prepared teachers will obviously increase positive learning outcomes. Ultimately, the findings from this study show that effective teacher instructional strategies will positively influence the classroom environment, which will increase positive learning outcomes.

\section{Conclusion}

This study makes the following conclusions:

I. Educational level a teacher is not significantly associated with his teaching strategies. However, the gender of the teacher and teaching experience are positively associated with effective instructional strategies. This is in line with previous studies which alluded that the gender of the teacher will influence his teaching strategies while taking into account student gender (Dee, 2007; Holmlund \& Sund, 2008). The study further concludes that teachers with substantial years of teaching experience have effective instructional strategies which influence positive learning outcomes. These findings concur with those of (Mitnik, Recabarren, Nussbaum, \& Soto, 2009) and this study will authoritatively conclude that teachers with many years of teaching experience deserve a structured continuous teacher professional development to increase sustainable learning outcomes. This is in line with the theory of diminishing returns of teacher experience.

II. The second conclusion drawn in this study is that effective teacher instructional is pertinent in student achievement. Some of the effective instructional strategies revolve around teacher preparedness for the instructional process, effective student engagement, instructional delivery strategies, and classroom discipline are vital for effective teaching and learning in classrooms. These findings concur with those of Ronfeldt, Brockman, and Campbell (2018), which established that effective instructional strategies would minimise wastage of quality learning time, increase learner engagement and sustainable student performance.

III. In conclusion, therefore, this study concludes that to realise learning outcomes, teachers need to utilise effective teaching strategies which range from effective teacher instructional preparedness, effective instructional delivery, effective teacher-student engagement, and effective teacher management of classroom discipline. This study recommends that teachers in Ghana must embrace these effective instructional strategies in their quest to realise sustainable learning outcomes.

\section{References}

Adu-Gyamfi, S., Donkoh, W. J., \& Addo, A. A. (2016). Educational reforms in Ghana: Past and present. Journal of Education and Human Development, 5(3), 158-172. https://doi.org/10.15640/jehd.v5n3a17 
Andersen, I. G., \& Reimer, D. (2019). Same-gender teacher assignment, instructional strategies, and student achievement: New evidence on the mechanisms generating same-gender teacher effects. Research in Social Stratification and Mobility. https://doi.org/10.1016/j.rssm.2019.05.001

Baeten, M., Dochy, F., Struyven, K., Parmentier, E., \& Vanderbruggen, A. (2016). Student-centred learning environments: an investigation into student teachers' instructional preferences and approaches to learning. Learning environments research, 19(1), 43-62. https://doi.org/10.1007/s10984-015-9190-5

Chick, N., \& Hassel, H. (2009). " Don't Hate Me Because I'm Virtual": Feminist Pedagogy in the Online Classroom. Feminist Teacher, 19(3), 195-215. https://doi.org/10.1007/s10984-015-9190-5

Day, C., Gu, Q., \& Sammons, P. (2016). The impact of leadership on student outcomes: How successful school leaders use transformational and instructional strategies to make a difference. Educational Administration Quarterly, 52(2), 221-258. https://doi.org/10.1177/0013161X15616863

Dee, T. S. (2007). Teachers and the gender gaps in student achievement. Journal of human resources, 42(3), 528-554. https://doi.org/10.3386/w11660

Di Biase, R. (2019). Moving beyond the teacher-centred/learner-centred dichotomy: implementing a structured model of active learning in the Maldives. Compare: $A$ Journal of Comparative and International Education, 49(4), 565-583. https://doi.org/10.1080/03057925.2018.1435261

Drinkwater, M. J., Gannaway, D., Sheppard, K., Davis, M. J., Wegener, M. J., Bowen, W. P., \& Corney, J. F. (2014). Managing active learning processes in large first year physics classes: The advantages of an integrated approach. Teaching and Learning Inquiry, 2(2), 75-90. https://doi.org/10.1037/st10000124

Holmlund, H., \& Sund, K. (2008). Is the gender gap in school performance affected by the sex of the teacher? Labour economics, 15(1), 37-53. https://doi.org/10.3102/0162373718819830

Illeris, K. (2018). A comprehensive understanding of human learning. Contemporary theories of learning, 1-14. Routledge.

Jones, L. (2007). The student-centered classroom. New York: Cambridge University Press.

Kang, J., \& Keinonen, T. (2018). The effect of student-centered approaches on students' interest and achievement in science: Relevant topic-based, open and guided inquiry-based, and discussion-based approaches. Research in Science Education, 48(4), 865-885. https://doi.org/10.1016/j.compedu.2009.02.01029

Li, Y., Flowerdew, J., \& Cargill, M. (2018). Teaching English for Research Publication Purposes to science students in China: A case study of an experienced teacher in the classroom. Journal of English for Academic Purposes, 35, 116-129. 
https://doi.org/10.1037/st100001246

McKnight, K., O'Malley, K., Ruzic, R., Horsley, M. K., Franey, J. J., \& Bassett, K. (2016). Teaching in a digital age: How educators use technology to improve student learning. Journal of research on technology in education, 48(3), 194-211. https://doi.org/10.1080/15391523.2016.1175856

Mitnik, R., Recabarren, M., Nussbaum, M., \& Soto, A. (2009). Collaborative robotic instruction: A graph teaching experience. Computers \& Education, 53(2), 330-342. https://doi.org/10.1016/j.compedu.2009.02.010

Morrison, G. R., Ross, S. J., Morrison, J. R., \& Kalman, H. K. (2019). Designing effective instruction: Wiley. https://doi.org/10.1037/st1000012445

Olayinka, A.-R. B. (2016). Effects of Instructional Materials on Secondary Schools Students' Academic Achievement in Social Studies in Ekiti State, Nigeria. World Journal of Education, 6(1), 32-39. https://doi.org/10.3102/01623737188198309

Riordan, R. J., Hine, M. J., \& Smith, T. C. (2019). An integrated learning approach to teaching an undergraduate information systems course. Journal of Information Systems Education, 28(1), 5. https://doi.org/10.20343/teachlearninqu.5.2.5

Ronfeldt, M., Brockman, S. L., \& Campbell, S. L. (2018). Does cooperating teachers' instructional effectiveness improve preservice teachers' future performance? Educational researcher, 47(7), 405-418. https://doi.org/10.1037/st10000164

Starkey, L. (2019). Three dimensions of student-centred education: a framework for policy and practice. Critical Studies in Education, 60(3), 375-390. https://doi.org/10.1080/15391523.2016.1175856

van de Kuilen, H. S., Altinyelken, H. K., Voogt, J. M., \& Nzabalirwa, W. (2019). Policy adoption of learner-centred pedagogy in Rwanda: A case study of its rationale and transfer mechanisms. International Journal of Educational Development, 67, 64-72. https://doi.org/10.3102/01623737188198306.

\section{Copyright Disclaimer}

Copyright for this article is retained by the author(s), with first publication rights granted to the journal. This is an open-access article distributed under the terms and conditions of the Creative Commons Attribution license (http://creativecommons.org/licenses/by/3.0/). 